\title{
Effects of vibration resistance exercise on strength, range of motion, function, pain and quality of life in persons with tennis elbow
}

\author{
Jong-Hun Lim ${ }^{a}$, Won-Seob Shin ${ }^{a, b}$ \\ ${ }^{a}$ Department of Physical Therapy, Graduate School of Health and Medicine, Daejeon University, Daejeon, Republic of Korea \\ ${ }^{\mathrm{b}}$ Department of Physical Therapy, Collage of Health and Medical Science, Daejeon University, Daejeon, Republic of Korea
}

Objective: The purpose of this study was to investigate the effects of vibration resistance exercise (VRE) in patients with tennis elbow on strength, range of motion (ROM), function, pain and quality of life (QOL).

Design: Randomized controlled trial.

Methods: Twenty-seven participants were randomly assigned to either the VRE group ( $\mathrm{n}=9$ ), weight resistance exercise (WRE) group $(n=9)$ or control group $(n=9)$. Each group underwent hot compress for 15 minutes and electrotherapy for 15 minutes. The VRE group underwent exercises using a vibrating ball for 5 minutes. The WRE group underwent exercises using dumbbells for 5 minutes. All participants were evaluated on wrist extension strength using a hand-held dynamometer, grip strength level through an electric dynamometer, and ROM through a smartphone goniometer application before and after intervention. Patient-rated tennis elbow evaluation, Visual Analogue Scale and Short Form 8 were measured by questionnaires.

Results: There were showed significant differences among the VRE, WRE and control group in wrist extensor muscle and hand grip strength, ROM, elbow function, pain and QOL after intervention $(p<0.05)$. The VRE group showed a greater significant improvement in wrist extensor muscle strength and elbow function compared with the others $(p<0.05)$. The VRE and the WRE groups had a more significant improvement in wrist extensor muscle and hand grip strength, ROM and pain compared with the control group $(p<0.05)$. However, there were no significant differences in QOL among the three groups.

Conclusions: Combining VRE with thermotherapy and electrotherapy appears to be more effective in improving wrist extension strength, ROM, elbow function, QOL in tennis elbow patients.

Key Words: Strength training, Tennis elbow, Vibration

\section{Introduction}

Tennis elbow is a disease that has a variety of different names, such as lateral epicondylitis, lateral epicondylosis, lateral epicondylalgia $[1,2]$.

Tennis elbow is an inflammatory disease that commonly occurs in the common extensor tendon located in the outer elbow [3]. Tennis elbow an endemic that mainly occurs in the dominant hand of adults between the ages 35-54 years old [4], is prevalent within $1 \%-3 \%$ of the adult population
[5], and has no specific differences between men and women [6]. Tennis elbow is one of the most common musculoskeletal diseases that occurs mainly in the outer elbow [7] with pain perceived in the outer elbow during resisted wrist and finger extension [2].

Pain is often radiated into the wrist and forearm [8]. These impairments produce handgrip weakness, and with pain occurring during wrist movements in the radial deviation, the use of the hand is restricted during daily life activities [8]. Pain occurring with tennis elbow is generally long-lasting,

Received: 11 October, 2016 Revised: 26 October, 2016 Accepted: 30 October, 2016

Corresponding author: Won-Seob Shin

Department of Physical Therapy, Daejeon University, 62 Daehak-ro, Dong-gu, Daejeon 34520, Republic of Korea

Tel: 82-42-280-2294 Fax: 82-42-280-2290 E-mail: shinws@dju.kr

(c) This is an Open-Access article distributed under the terms of the Creative Commons Attribution Non-Commercial License (http://creativecommons.org/licens es/by-nc/4.0) which permits unrestricted non-commercial use, distribution, and reproduction in any medium, provided the original work is properly cited.

Copyright $@ 2016$ Korean Academy of Physical Therapy Rehabilitation Science 
and pain is likely to recur in the next few days even after recovery $[9,10]$. These problems lead to several other problems in life in which the ability to perform personal tasks and activities at home are impaired, thus contributing to economic loss, and subsequently reducing quality of life [11].

Physical therapy intervention for acute tennis elbow includes cold therapy, heat therapy for chronic conditions, relaxation and ultrasound, microwave therapy, electrical stimulation, muscle stretching, strengthening exercises, and use of a brace [12]. In addition, taping of the muscles in the elbow region [13] joint mobilization technique [2,14] are also known to be effective treatment techniques. Dynamic external resistance exercises are performed using weights or dumbbells for strengthening and rehabilitation exercises as a musculoskeletal intervention.

When lowering or lifting a certain weight load, muscle pain arises due to maximum load being put at only one point within the joint range of motion, which can lead to difficulties in performing exercises for tennis elbow treatment [15].

Vibration treatment is effective in improving motor function, metabolic rate, and increase blood flow, which subsequently reduces inflammation and muscular damage compared to dynamic external resistance exercises [16,17].

Currently, the whole body vibration is being used as an exercise method for functional improvement $[18,19]$ which not only stimulates the muscles directly receiving the vibration stimulation, but also has an effect on adjacent muscles as well [20].

A previous study reported significant improvements in jumping ability and lower extremity muscle strength after undergoing whole body vibration training for 4 months [21]. Whole body vibration had an effect on decreasing inflammation and pain after the occurrence of delayed onset of muscle soreness occurs after running [22]. Previous studies have reported that muscle training with vibration stimulus is effective in improving flexibility, postural control, balance, and coordination [23-25].

Although the previous studies report a positive influence of oscillatory motion, the vibration stimulus was applied to the whole body rather than a local area for certain muscles, and the effect is limited to being seen in the lower extremity rather than the upper extremity. Studies where the effects of applying local oscillation stimulation on the upper extremity for a musculoskeletal problem are insufficient Therefore, the purpose of this study was to evaluate the effect of applying localized vibrational motion on the upper extremity on wrist muscle strength, joint range of motion, function, pain, and quality of life in patients with tennis elbow.

\section{Methods}

\section{Subject}

This study included subjects who were diagnosed with tennis elbow and were admitted and receiving physical therapy from the A rehabilitation center in Daejeon.

The inclusion criteria were positive results on the Thomsen test, resisted middle finger test, and Mill's test [26], while the exclusion criteria were subjects with complaints of severe wrist pain, subjects who were currently receiving injections or medication, those who were having to undergo surgery, those with another orthopedic disease requiring surgery, or those with pathological conditions such as diabetes or high blood pressure.

A total of twenty-seven subjects who had met the selection criteria were randomly divided into the vibration resistance exercise (VRE) group ( $\mathrm{n}=9$ ), weight resistance exercise (WRE) group ( $n=9)$ or the control group $(n=9)$. All subjects have voluntarily agreed to participate in the study after being aware of the study purpose and methods. This study was conducted with the approval of the institutional review board of the Daejeon University (IRB no. 1040647201606-HR-020-03).

\section{Procedure}

This study included the VRE, WRE, and control groups with intervention conducted three times a week for four weeks. The subjects in the control group received for $15 \mathrm{mi}-$ nutes and interferential current electrical therapy for 15 minutes. After the subjects in the VRE and WRE received therapy for 30 minutes, they had exercised for an addition of 5 minutes.

\section{Vibration resistance exercise group}

The Powerball (Powerball classic $250 \mathrm{~Hz}$; RPM Sports Ltd., Contae Thiobraid Árann, Ireland) was created for exercise purposes without applying excessive force on the joints and muscles. While sitting in an upright posture with the affected arm placed on an armrest with 90 degrees of elbow flexion and forearm pronation, the subjects used their wrist rotate the Powerball out towards the body for $5 \mathrm{mi}-$ nutes [27]. Subjects used the Powerball after they had been fully informed and trained of the use of the equipment (Figure 1A). 

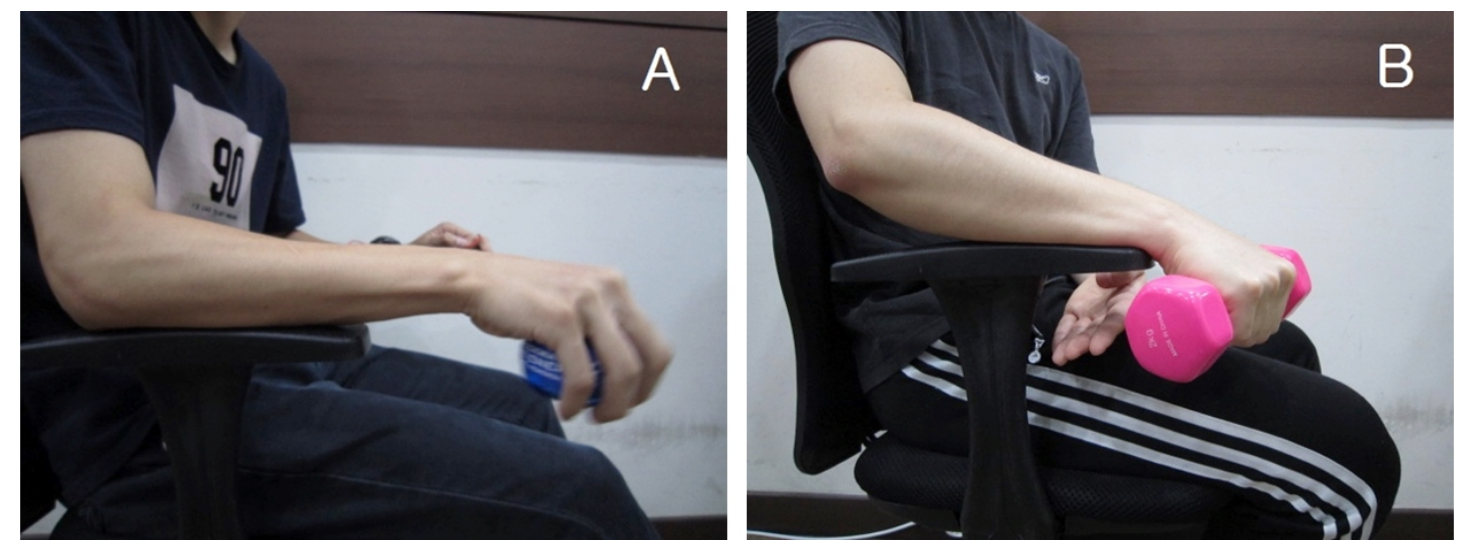

Figure 1. (A) Vibration resistance exercise. (B) Weight resistance exercise.

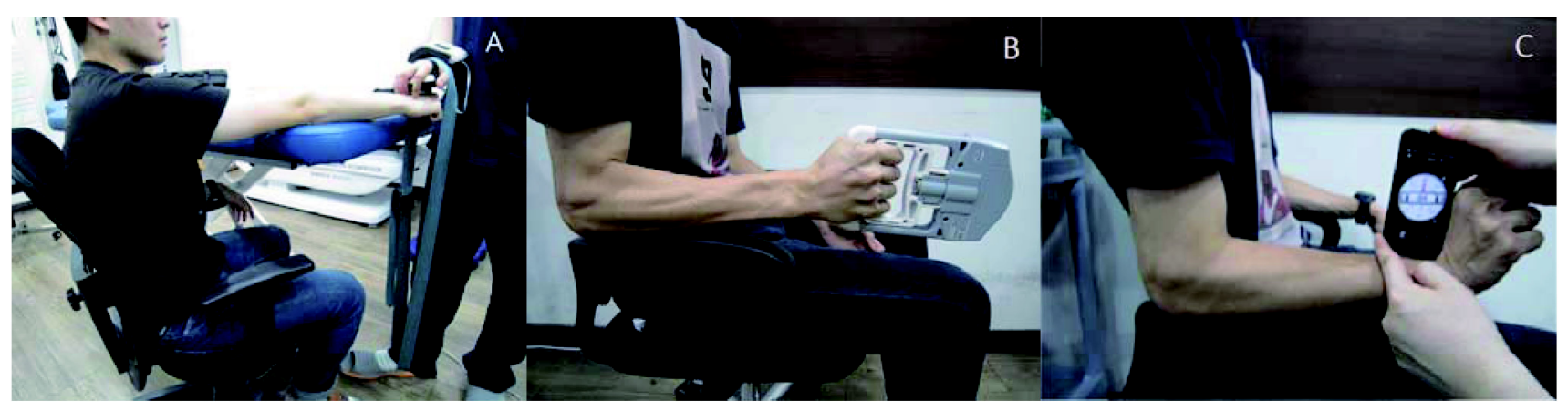

Figure 2. (A) Wrist extensor strength. (B) Hand-grip strength. (C) Joint range of motion evaluation.

\section{Weight resistance exercise group}

WRE were performed eccentrically with a $2 \mathrm{~kg}$ dumbbell for men and a $1 \mathrm{~kg}$ dumbbell for women for 5 minutes [28]. Subjects sat on a chair with armrests with the affected elbow raised, and after raising the arm off the arm rest with elbow flexion and forearm pronation, wrist contractions were repeated up to the extent where there was no pain in the mid-range of motion using only the wrist (Figure 1B).

\section{Outcome measures}

\section{Strength assessment}

\section{Wrist extensor muscle strength}

After placing the upper extremity on a table with the 90 degrees of shoulder flexion, elbow extension, forearm pronation, and 20 degrees of wrist extension, the maximal isometric extension force of the wrist extensors was assessed using the portable PowerTrack II Commander hand-held dynamometer (JTech Medical, Midvale, UT, USA) [29]. Strength assessments were carried out three times, with a 1-minute rest period between each assessment (Figure 2A) [30].

\section{Hand-grip strength}

The baseline digital Smedley spring dynamometer (Sammons Preston, Bolingbrook, IL, USA) was used to assess handgrip strength. In a seated position with the subject's upper extremity placed on an armrest, elbow was in 90 degrees flexion, and forearm and wrist in neutral position, hand-grip strength was assessed by having the subject pull the handle of the dynamometer to their maximum ability while the upper extremity was held 15 degrees in front of the trunk (Figure 2B) [31].

The dynamometer has an interrater reliability of 0.93 0.94 [32].

\section{Joint range of motion evaluation}

With the wrist in neutral position, the angle achieved during maximum wrist extension was assessed using the Clinometer (Plaincode Software Solution, Stephanskirchen, Germany) which is a smartphone application. 
Table 1. General characteristics of subjects

$(\mathrm{N}=27)$

\begin{tabular}{lcccc}
\hline \multicolumn{1}{c}{ Characteristic } & VRE group $(\mathrm{n}=9)$ & WRE group $(\mathrm{n}=9)$ & Control group $(\mathrm{n}=9)$ & $\chi^{2} / \mathrm{F}$ \\
\hline Gender $($ male/female) & $6 / 3$ & $5 / 4$ & $9 / 0$ & 5.014 \\
Age $(\mathrm{y})$ & $42.44(7.945)$ & $41.78(7.48)$ & $39.78(4.68)$ & 0.369 \\
Height $(\mathrm{cm})$ & $168.89(10.09)$ & $165.78(10.23)$ & $173.56(3.40)$ & 1.897 \\
Weight $(\mathrm{kg})$ & $65.67(12.72)$ & $65.89(11.23)$ & $74.11(5.42)$ & 1.971 \\
Dominant side $(\mathrm{Rt} / \mathrm{Lt})$ & $8 / 1$ & $9 / 0$ & $9 / 0$ & 2.077 \\
Side of lesion $(\mathrm{Rt} / \mathrm{Lt})$ & $6 / 3$ & $6 / 3$ & $8 / 1$ & 1.543 \\
\hline
\end{tabular}

Values are presented as number only or mean (SD).

VRE: vibration resistance exercise, WRE: weight resistance exercise, Rt: right, Lt: left.

With the forearm placed on the chair armrest, with 90 degrees of elbow flexion, the angle between the radius and the second metacarpal was measured by the radial styloid axis of the forearm in pronation. The interrater reliability for angular measurements was 0.76-0.95 (Figure 2C) [33].

\section{Evaluation of elbow functional ability}

The patient-rated tennis elbow evaluation (PRTEE) is a questionnaire that includes 5 questions related to pain, 6 questions related to special activities, and 4 questions about general activities, totaling up to 15 questions with 0 being the highest score and 10 being the lowest score. The five pain-related questions add up to 50 points, and the 10 activity-related questions add up to 50 points (special activities + general activities) totaling up to 100 points [34]. The PRTEE evaluation has an interrater reliability of .96 , with lower scores indicating a higher level of elbow function.

\section{Pain levels}

To assess the level of elbow pain, the visual analogue scale (VAS) using a $10 \mathrm{~cm}$ line was used where the line is divided into $1 \mathrm{~cm}$ segments with $0 \mathrm{~cm}$ indicating no pain and $10 \mathrm{~cm}$ indicating excruciating pain. The VAS evaluation method for pain is high in reliability and validity [35].

\section{Quality of living}

The form includes 8 items including questions about general health, physical functioning, physical role limitations, pain, vitality, social function, mental, and emotional role limitations with higher scores indicating a higher quality of life. The reliability of the assessment has a Cronbach's value of 0.82 [14].

\section{Data and statistical analysis}

For this study, the PASW Statistics ver. 18.0 program
(IBM Co., Armonk, NY, USA) was used for data analysis. The general characteristics of subjects were described using the mean and standard deviation values, and the ShapiroWilks test was performed in order to verify the normality of the subjects.

The paired t-test was used to compare between two groups before and after intervention and a one-way ANOVA was used to compare the differences in the amount of change between each group. The significance level was set at $\alpha=$ 0.05 .

\section{Results}

A total of twenty-seven participants were included in the study with 9 subjects in the VRE group, 9 subjects in the WRE group, and 9 subjects in the control group. There was no significant difference in gender, age, height, weight, side of dominance, between the three groups ( $p>0.05$; Table 1$)$.

There was a significant difference in wrist extensor strength, hand-grip strength, wrist range of motion, functional ability of the elbow, pain levels and quality of life between each group before and after intervention, there was a significant difference $(p<0.05)$.

In comparison of the three groups, the VRE group showed a significant increase in muscle strength and functional performance compared to the WRE and control group $(p<0.05)$. The VRE and WRE group showed a significant improvement in the change values of extensor muscle strength, hand grip, wrist range of motion, and pain levels compared to the control group $(p<0.05)$. However, there was no significant difference between the three groups in quality of life pre and post intervention (Table 2). 
Table 2. Pre-post intervention comparison of three groups $(\mathrm{N}=27)$

\begin{tabular}{|c|c|c|c|c|c|}
\hline & & VRE group $(\mathrm{n}=9)$ & WRE group $(n=9)$ & Control group $(n=9)$ & $\mathrm{F}$ \\
\hline \multirow[t]{4}{*}{ Strength (N) } & Pre & $104.15(38.65)$ & 83.37 (36.39) & 123.15 (20.93) & 3.282 \\
\hline & Post & $137.07(35.54)$ & $100.96(38.54)$ & $129.81(20.97)$ & 3.090 \\
\hline & $\mathrm{t}$ & $-20.096^{*}$ & $-7.043^{*}$ & $-6.719^{*}$ & \\
\hline & Change value & $23.93(4.92)^{\mathrm{a}, \mathrm{b}}$ & $17.59(7.49)^{\mathrm{a}}$ & $6.67(2.98)$ & $52.681^{*}$ \\
\hline \multirow[t]{4}{*}{ Handgrip (kg) } & Pre & $34.43(9.50)$ & $27.76(11.20)$ & $36.40(6.47)$ & 2.153 \\
\hline & Post & $43.34(9.80)$ & $35.93(11.03)$ & $39.11(6.92)$ & 1.406 \\
\hline & $\mathrm{t}$ & $-14.675^{*}$ & $-13.331^{*}$ & $-7.338^{*}$ & \\
\hline & Change value & $8.91(1.82)^{\mathrm{a}}$ & $8.18(1.84)^{\mathrm{a}}$ & $2.71(1.11)$ & $39.056^{*}$ \\
\hline \multirow[t]{4}{*}{$\operatorname{ROM}\left({ }^{\circ}\right)$} & Pre & $63.77(7.25)$ & $63.89(10.91)$ & $69.00(4.82)$ & 1.236 \\
\hline & Post & $76.11(6.91)$ & 74.47 (11.49) & $72.33(4.67)$ & 0.481 \\
\hline & $\mathrm{t}$ & $-7.588^{*}$ & $-7.640^{*}$ & $-7.559^{*}$ & \\
\hline & Change value & $12.34(4.88)^{\mathrm{a}}$ & $10.58(4.15)^{\mathrm{a}}$ & $3.33(1.32)$ & $14.376^{*}$ \\
\hline \multirow[t]{4}{*}{ PRTEE (score) } & Pre & $46.67(12.93)$ & $48.17(4.95)$ & $45.11(5.04)$ & 0.290 \\
\hline & Post & $16.50(5.61)$ & $31.67(9.26)$ & $29.33(6.21)$ & 11.562 \\
\hline & $\mathrm{t}$ & $7.120^{*}$ & $4.495^{*}$ & $7.130^{*}$ & \\
\hline & Change value & $-30.17(12.71)^{\mathrm{a}, \mathrm{b}}$ & $-16.50(11.01)$ & $-15.78(6.64)$ & $5.429^{*}$ \\
\hline \multirow[t]{4}{*}{ VAS (cm) } & Pre & $5.67(1.22)$ & $5.33(0.71)$ & $4.78(0.97)$ & 1.849 \\
\hline & Post & $2.33(1.00)$ & $2.22(1.09)$ & $3.11(0.60)$ & 2.478 \\
\hline & $\mathrm{t}$ & $8.165^{*}$ & $7.353^{*}$ & $5.774^{*}$ & \\
\hline & Change value & $-3.33(1.22)^{\mathrm{a}}$ & $-2.11(0.93)^{\mathrm{a}}$ & $-1.22(0.44)$ & $5.727^{*}$ \\
\hline \multirow[t]{4}{*}{ SF-8 (score) } & Pre & $58.61(13.51)$ & $56.46(5.72)$ & $61.67(10.44)$ & 0.571 \\
\hline & Post & $74.10(12.29)$ & 72.78 (7.89) & $71.74(10.47)$ & 0.117 \\
\hline & $\mathrm{t}$ & $-6.164^{*}$ & $-5.619^{*}$ & $-18.125^{*}$ & \\
\hline & Change value & $15.49(7.54)$ & $16.32(8.71)$ & $10.07(1.67)$ & 2.294 \\
\hline
\end{tabular}

Values are presented as mean (SD).

VRE: vibration resistance exercise, WRE: weight resistance exercise, ROM: range of motion, PRTEE: patient-rated tennis elbow evaluation, VAS: visual analogue scale, SF-8: short form 8.

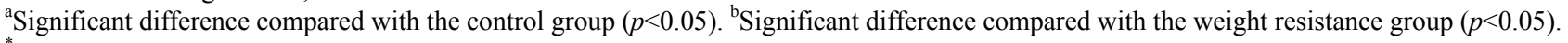
${ }^{*} p<0.05$.

\section{Discussion}

The purpose of this study was to investigate the effects of applying vibration resistance movement on elbow muscle strength, range of motion, pain levels, and quality of life in patients with tennis elbow. After four weeks of intervention, greater changes in elbow muscle strength and function were observed in the VRE group compared to the WRE group. In this study, elbow muscle strength, function, pain levels were significantly improved post intervention in the VRE, WRE, and control group subjects. There were greater changes that have been observed in the VRE group, and these results are consistent with previous studies where the application of vibration stimulus was reported to be effective in pain relief and functional improvement in patients with low back pain [36]. In addition, significant increases in muscle flexibility have been observed in other studies [37]. Even when performing leg press exercises with the same load, subjects were able to withstand greater amounts of weight bearing when subjected to vibration stimuli [38]. Therefore, improved pain relief, exercise capacity, and flexibility has been observed with the use of VREs.

Muscle strength, joint range of motion, elbow function, and pain levels in the control group also improved significantly post intervention; however, this may be due to the application of a hot pack and electrical treatment.

The WRE group showed a significant improvement in muscle strength, endurance, and pain compared to the control group, and the results of improved muscle strength are similar to those from previous studies where the ability of the muscle to withstand stress and pain thresholds by applying stress onto the muscles [39].

The short form 8 , which is used to assess quality of life, showed that there were significant improvements in the WRE, WRE, and control group, but no significant difference in between groups. There were decreased levels of pain 
in which it was related to the ability to control pain in all three groups, and thus having contributed to the changes in quality of life.

Tennis elbow is caused by a strong impact from a sudden opposite direction during wrist extension, and due to the damaged muscle receiving repetitive stress, the normal healing process is prevented, and thus, triggering pain [40].

When the lateral part of the elbow is directly palpated, pain arises, which is characterized by a decrease in grip strength [41], and a resulting reduction of muscle strength and function [42].

The results of this study showed that application of VRE had an effect on muscle strength, joint range of motion, pain and quality of life in those with tennis elbow. The results showed that it is possible for application of vibration stimuli to clinically improve muscle strength, joint range of motion, elbow function and elbow pain in patients with tennis elbow. For this study, the Powerball was used to provide VRE, which is considered to be simple, does not require the use of heavy dumbbells, and is possible to overcome the disadvantages of using dumbbells for resistance exercises.

In addition, the advantages of using the Powerball includes being easy to carry, and the VREs can be can be implemented without being concerned of time or space restraints.

One limitation of this study was that the subjects were between the ages of 35 to 55 years old, therefore, the possible effects on other age groups is not known. Also, since the vibration resistance was only applied in a circular motion on the wrist, movement effects on various directions are not known. Therefore, further studies that will investigate the effects of applying VREs using a variety of methods are needed.

\section{Conflict of Interest}

The authors declared no potential conflicts of interest with respect to the authorship and/or publication of this article.

\section{References}

1. Noteboom T, Cruver R, Keller J, Kellogg B, Nitz AJ. Tennis elbow: a review. J Orthop Sports Phys Ther 1994;19:357-66.

2. Vicenzino B, Collins D, Wright A. The initial effects of a cervical spine manipulative physiotherapy treatment on the pain and dysfunction of lateral epicondylalgia. Pain 1996;68:69-74.

3. Schnatz P, Steiner C. Tennis elbow: a biomechanical and ther- apeutic approach. J Am Osteopath Assoc 1993;93:778, 782-8.

4. Norris CM. Sport injuries: diagnosis and management. Oxford: Butterworth-Heinemann; 1998.

5. Hong QN, Durand MJ, Loisel P. Treatment of lateral epicondylitis: where is the evidence? Joint Bone Spine 2004;71: 369-73.

6. Shiri R, Viikari-Juntura E. Lateral and medial epicondylitis: role of occupational factors. Best Pract Res Clin Rheumatol 2011; 25:43-57.

7. Potter HG, Hannafin JA, Morwessel RM, DiCarlo EF, O'Brien SJ, Altchek DW. Lateral epicondylitis: correlation of MR imaging, surgical, and histopathologic findings. Radiology 1995;196: 43-6.

8. Sran M, Souvlis T, Vicenzino B, Wright A. Characterisation of chronic lateral epicondylalgia using the McGill pain questionnaire, visual analog scales, and quantitative sensory tests. Pain Clinic 2001;13:251-9.

9. Bernhang AM. The many causes of tennis elbow. N Y State J Med 1979;79:1363-6.

10. Binder AI, Hazleman BL. Lateral humeral epicondylitis--a study of natural history and the effect of conservative therapy. Br J Rheumatol 1983;22:73-6.

11. Labelle H, Guibert R, Joncas J, Newman N, Fallaha M, Rivard $\mathrm{CH}$. Lack of scientific evidence for the treatment of lateral epicondylitis of the elbow. An attempted meta-analysis. J Bone Joint Surg Br 1992;74:646-51.

12. Smidt N, Assendelft WJ, van der Windt DA, Hay EM, Buchbinder R, Bouter LM. Corticosteroid injections for lateral epicondylitis: a systematic review. Pain 2002;96:23-40.

13. Lee MH, Park RJ. The effects of ultra sound and taping treatment on the pain and grip strength in lateral epicondylitis. J Korean Phys Ther 2004;16:125-38.

14. Bost JE, Williams BA, Bottegal MT, Dang Q, Rubio DM. The 8 -item Short-Form Health Survey and the physical comfort composite score of the quality of recovery 40 -item scale provide the most responsive assessments of pain, physical function, and mental function during the first 4 days after ambulatory knee surgery with regional anesthesia. Anesth Analg 2007;105:1693700

15. Kisner C, Colby LA. Therapeutic exercise: foundations and techniques. 6th ed. Philadelphia: F.A. Davis Company; 2012.

16. Cardinale M, Soiza RL, Leiper JB, Gibson A, Primrose WR. Hormonal responses to a single session of wholebody vibration exercise in older individuals. Br J Sports Med 2010;44:284-8.

17. Hubbard RJ, Petrofsky JS, Lohman E, Berk L, Thorpe D. Plyometrics and vibration: no clear winner on efficacy. Phys Ther Rehabil Sci 2014;3:86-92.

18. Gusso S, Munns CF, Colle P, Derraik JG, Biggs JB, Cutfield WS, et al. Effects of whole-body vibration training on physical function, bone and muscle mass in adolescents and young adults with cerebral palsy. Sci Rep 2016;6:22518.

19. Park J, Choi W, Lee S. Effects of immediate unilateral whole body vibration on muscle performance and balance in young adults. Phys Ther Rehabil Sci 2013;2:115-8.

20. Ritzmann R, Gollhofer A, Kramer A. The influence of vibration type, frequency, body position and additional load on the neuromuscular activity during whole body vibration. Eur J Appl Physiol 2013;113:1-11 
21. Torvinen S, Kannus P, Sievänen H, Järvinen TA, Pasanen M, Kontulainen $\mathrm{S}$, et al. Effect of four-month vertical whole body vibration on performance and balance. Med Sci Sports Exerc 2002; 34:1523-8.

22. Broadbent S, Rousseau JJ, Thorp RM, Choate SL, Jackson FS, Rowlands DS. Vibration therapy reduces plasma IL6 and muscle soreness after downhill running. Br J Sports Med 2010;44:88894.

23. Cochrane DJ, Stannard SR. Acute whole body vibration training increases vertical jump and flexibility performance in elite female field hockey players. Br J Sports Med 2005;39:860-5.

24. Sands WA, McNeal JR, Stone MH, Russell EM, Jemni M. Flexibility enhancement with vibration: acute and long-term. Med Sci Sports Exerc 2006;38:720-5.

25. Asakawa Y, Lee MM, Song CH. The effect of whole body vibration training on postural sway in patients with spinal cord injury: a pilot study. Phys Ther Rehabil Sci 2013;2:70-4.

26. Stasinopoulos D, Stasinopoulos I. Comparison of effects of Cyriax physiotherapy, a supervised exercise programme and polarized polychromatic non-coherent light (Bioptron light) for the treatment of lateral epicondylitis. Clin Rehabil 2006;20:12-23.

27. Legg JP. The effect of Powerball on grip strength [Master degree]. Johannesburg: Johannesburg University; 2010.

28. Peterson M, Butler S, Eriksson M, Svärdsudd K. A randomized controlled trial of eccentric vs. concentric graded exercise in chronic tennis elbow (lateral elbow tendinopathy). Clin Rehabil 2014;28:862-72.

29. Phillips BA, Lo SK, Mastaglia FL. Muscle force measured using "break" testing with a hand-held myometer in normal subjects aged 20 to 69 years. Arch Phys Med Rehabil 2000;81:653-61.

30. Toemen A, Dalton S, Sandford F. The intra- and inter-rater reliability of manual muscle testing and a hand-held dynamometer for measuring wrist strength in symptomatic and asymptomatic subjects. Hand Therapy 2011;16:67-74.

31. Mathiowetz V, Rennells C, Donahoe L. Effect of elbow position on grip and key pinch strength. J Hand Surg Am 1985;10:694-7.

32. Yoon MR, Choi HS, Shin WS. Effects of the abdominal drawing-in maneuver and the abdominal expansion maneuver on grip strength, balance and pulmonary function in stroke patients. J Korean Phys Ther 2015;27:147-53.

33. Park IW, Lim OB, Park KN, Yi CH. Intra- and inter-rater reliability of measuring passive range of shoulder motion with smartphone and goniometer in patients with stroke. Phys Ther Korea 2014;21:1-12.

34. Overend TJ, Wuori-Fearn JL, Kramer JF, MacDermid JC. Reliability of a patient-rated forearm evaluation questionnaire for patients with lateral epicondylitis. J Hand Ther 1999;12:31-7.

35. Wagner DR, Tatsugawa K, Parker D, Young TA. Reliability and utility of a visual analog scale for the assessment of acute mountain sickness. High Alt Med Biol 2007;8:27-31.

36. Rittweger J, Just K, Kautzsch K, Reeg P, Felsenberg D. Treatment of chronic lower back pain with lumbar extension and whole- body vibration exercise: a randomized controlled trial. Spine (Phila Pa 1976) 2002;27:1829-34

37. van den Tillaar R. Will whole-body vibration training help increase the range of motion of the hamstrings? J Strength Cond Res 2006;20:192-6.

38. Hwang SH, Cho YG, Sohn RH, Kim YH, Kim HS, Lim DH. Effects of strengthening exercise using vibrating leg-press $\mathrm{J}$ Biomed Eng Res 2009;30:221-5.

39. Kim JY, Seo WY, Park CH, Kim DW. Clinical results after a rehabilitation program for lateral epicondylitis of the elbow. $\mathrm{J}$ Korean Orthop Assoc 2011;46:380-6.

40. Shmushkevich Y, Kalichman L. Myofascial pain in lateral epicondylalgia: a review. J Bodyw Mov Ther 2013;17:434-9.

41. Haker E. Lateral epicondylalgia: diagnosis, treatment, and evaluation. Crit Rev Phys Rehabil Med 1993;5:129-154.

42. Kohia M, Brackle J, Byrd K, Jennings A, Murray W, Wilfong E. Effectiveness of physical therapy treatments on lateral epicondylitis. J Sport Rehabil 2008;17:119-36. 